\title{
Design Concept of an Automated Irrigation System for Simulating Saltwater Intrusion in a Mesocosm Experiment
}

\author{
Chengcheng Xu \\ Department of Civil Engineering, China Agricultural University, Beijing, China \\ Email: chengcheng.xu@uconn.edu
}

How to cite this paper: Xu, C.C. (2017) Design Concept of an Automated Irrigation System for Simulating Saltwater Intrusion in a Mesocosm Experiment. Engineering, 9, 563-574.

https://doi.org/10.4236/eng.2017.96035

Received: May 8, 2017

Accepted: June 26, 2017

Published: June 29, 2017

Copyright $\odot 2017$ by author and Scientific Research Publishing Inc. This work is licensed under the Creative Commons Attribution International License (CC BY 4.0).

http://creativecommons.org/licenses/by/4.0/

(c) (i) Open Access

\begin{abstract}
Coastal wetlands make up about one third of the overall wetland area in the conterminous United Stated based on the Environmental Protection Agency 2016 [1]. Sea-level rise is expected to elevate water salinity and effect carbon sequestration, nitrogen removal, further alter plant communities and shift ecosystem function. To promote understanding of the influence of seawater intrusion into tidal freshwater wetlands, we designed a mesocosm experiment with automated irrigation system at Spring Hill, Storrs, CT, USA $\left(41.8^{\circ} \mathrm{N}, 72.3^{\circ} \mathrm{W}\right)$. To simulate marine water intrusion, we designed an automated irrigation to work for an on-going mesocosm experiment, which is composed of 64 tanks with 4 wetland species: Carexstricta, Spartinapectinata, Typhalatifolia, Phragmitesaustralis. During low tide, solenoid valves quantify water based on the instruction of system core controller (Arduino) and water is distributed to assigned tank [2] [3]. During high tide, water is pumped up into assigned tank, salinity is varied with plant species, Carexstricta and Spartinapectinata are fresh water species, Typhalatifolia, Phragmitesaustralis are brackish water species. The manipulation core of system is an open-source microcontroller platform. The irrigation system was designed daily twice change from low tide water level to high tide water level, and same water tank should keep at constant salinity within 30 days. Staff just needs monthly visit to add sea salts, the raw material of artificial seawater. Ecosystem $\mathrm{CO}_{2}$ and $\mathrm{CH}_{4}$ gas exchanges were measured monthly from May to September 2015 using large transparent chambers that enclosed emergent plants and the soil surface; field sampling and analysis procedures followed [4]. The simulated saltwater intrusion results are expected to alter plant growth, emission of carbon dioxide, methane and other greenhouse gases, and effect interaction with coastal marsh ecosystem.
\end{abstract}

\section{Keywords}

Sea-Level Rise, Tidal Fresh Wetland, Salinization, Automated Irrigation 
System Arduino

\section{Introduction}

In order to understand the effect of tide elevation change on coastal marshes, we designed a mecocosm experiment site to relate the tide elevation gradient and carbon emission of typical wetland species, respectively Carexstricta, Spartinapectinata, Typhalatifolia, Phragmitesaustralis. Further, Carexstricta and Spartinapectinata are fresh-water grown plants; Typhalatifolia and Phragmitesaustralis are species commonly found in fresh to brackish wetlands Clump-forming species; Carexstricta, has higher levels of $\mathrm{CH}_{4}$ emissions than other growth forms such as clonal dominant grasses [5]. Invasive species like Typhalatifolia produce large amounts of aboveground biomass, Typhalatifolia is associated with increased $\mathrm{CH}_{4}$ production relative to less productive native communities [6]. Invasive strains of Phragmitesaustralis are a problematic and productive invader of coastal wetlands throughout eastern North America; Phragmitesaustralis is characterized by a high rate of biomass production as well as higher $\mathrm{CH}_{4}$ emissions as compared to native Phragmites strains and native wetland species [7]. In Phragmites-dominated zones, $\mathrm{CO}_{2}$ uptake and $\mathrm{CH}_{4}$ emissions are greater than native salt marsh areas dominated by Spartinapectinata [8]. Species composition is vital to determine how wetland emissions will change. Figure 1 shows the layout of the on-going mesocosm experiment. We randomly assigned wetland plants to 64 tanks; each tank has a volume of 100 gallon. Two kinds of water treatments are assigned to each species. Based on plants' tolerance to salinity and the salinity of the Connecticut River, salinity of fresh water treatment is at 0.05

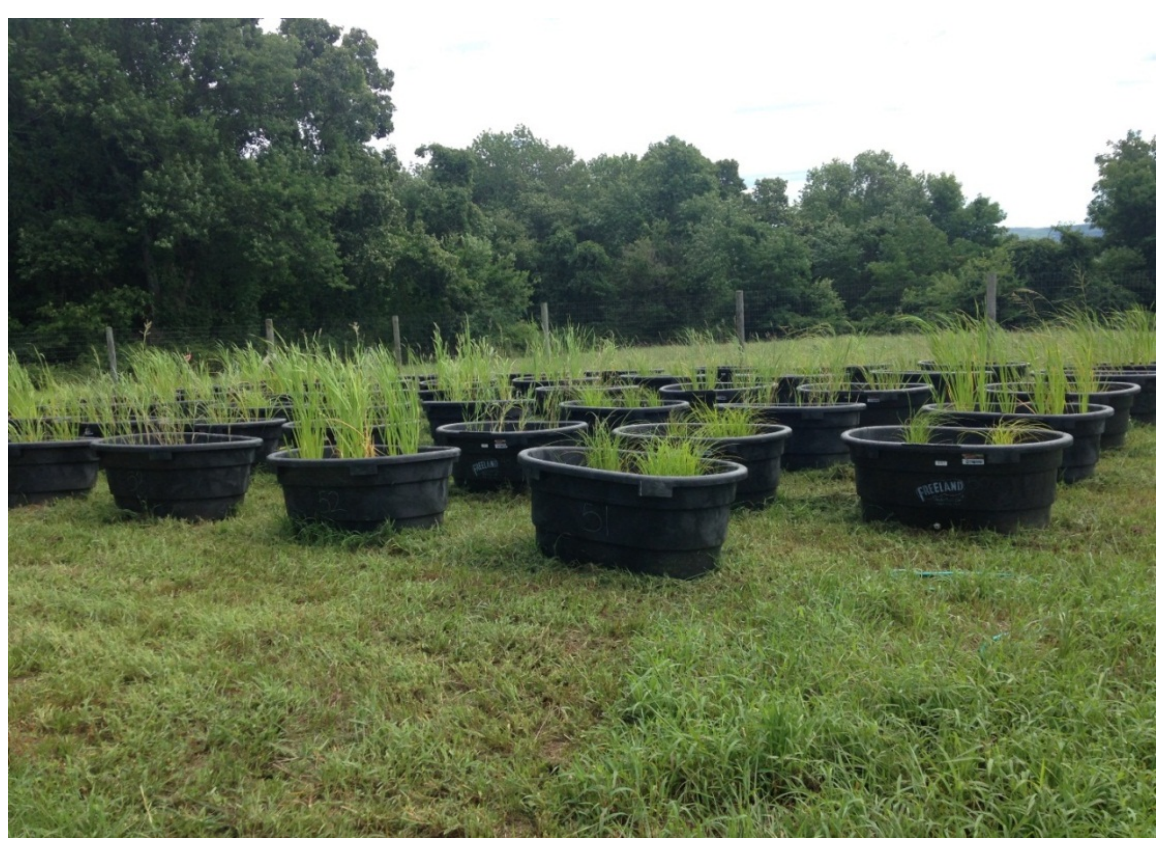

Figure 1. Mesocosm experiment layout. 
parts per thousand, salinity of brackish water treatment is at 0.1 parts per thousand. PVC pipeline system is used for tanks' connection, and it consists of two parts, the upper layer is for fresh water distribution, the lower layer is for brackish water distribution. North of 64 water tanks, a huge tank with a capacity of 32,000 gallons is planted to be filled with brackish water; 32,000 gallons of water capacity makes sure constant water supply to each "mesocosm" tank. There is a water pipe next to the huge tank, the water pipe is responsible for supplying fresh water, and distributing fresh water directly by PVC pipes. The diameter of PVC pipes is $1.5 \mathrm{~cm}$. Brackish water outflows from huge tank, the huge tank is connected to PVC pipe systems. Along PVC pipes, brackish water is distributed to randomly assigned tanks (8 replicates per species).

The automatic irrigation system will be driven by solar radiation; solar panel batteries will be located in the north of experiment site to supply electronic power for electronic components and peristaltic pump. The core of the entire system is Arduino microcontroller-open-source electronic prototyping platform, based on programming code, Arduino can control each system component. The automatic irrigation system does not require frequent field visits, with staff only needing to attend to the mesocosm experiment site monthly, primarily to add artificial seawater into huge tank.

The automatic irrigation system simulates the half-day tide in Connecticut River, that is, two high tides and two low tides per day. Based on the data from Connecticut weather, the difference height between high tide and low tide is 20 $\mathrm{cm}$ [9]. Figure 2 shows the distribution and location of 64 water tanks, red rectangle is huge tank, blue rectangular is solar panel batteries, and concentric circles are water pipe. Black oval is Typhalatifolia, green oval is Carexstricta, blue oval is Phragmitesaustralis, yellow oval is Spartinapectinata. At low tides, the

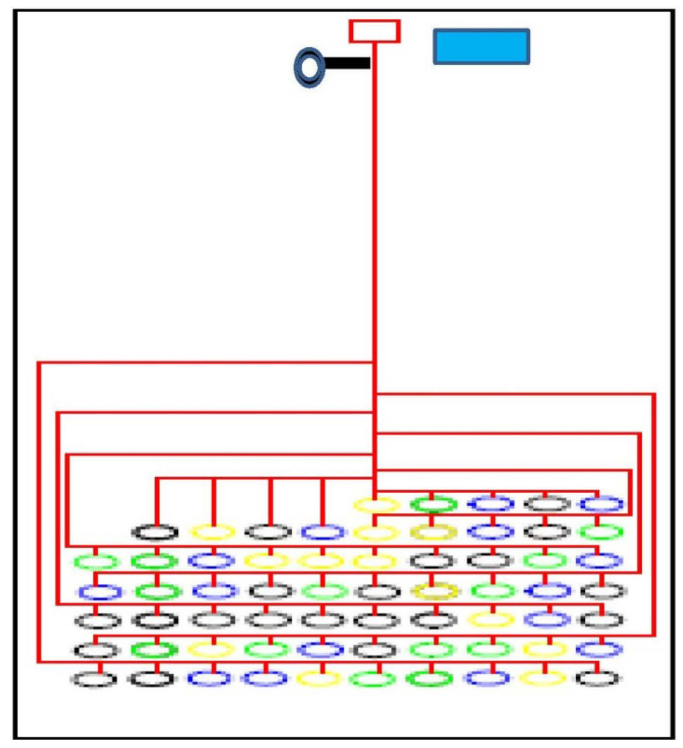

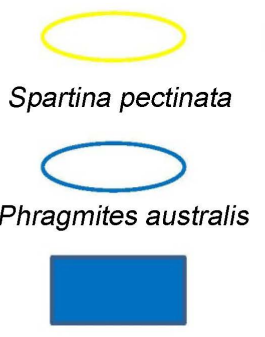

Solar panel batteries

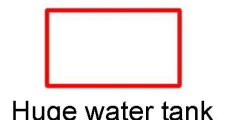

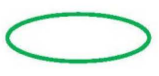

Carex stricta

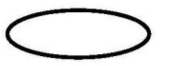

Typha latifolia

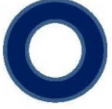

Water pipe

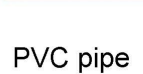

Figure 2. Distribution of 4 plant species, location of water pipe and solar panel batteries (The lower layer of pipe system is covered by that of upper layer, the lower layer cannot be shown on the figure). 
water level in the tank is at the same height of soil surface, the soil surface should be exposed, that is, the water level of low tide should be $35 \mathrm{~cm}$ high; at high tides, the water level is $20 \mathrm{~cm}$ higher than that of low tides, the water level of high tide should be $55 \mathrm{~cm}$. The artificial seawater we plan to use is made up of sea salt (spectrum) and fresh water, and keeps the salinity at $0.1 \mathrm{ppt}$. In South Carolina Neubauer et al. conducted an in situ saltwater intrusion experiment in a tidal marsh. Brackish water was manually added to replicate field plots twice per week, it resulted in an increase in salinity [4]. Dong Y. Lee et al. designed and deployed an in situ automatic irrigation system, they have increased the salinity of a tidal freshwater wetland to oligohaline levels in near-surface soils, 17 plant species are observed and a local creek supplies fresh water [10].

\section{The System Components}

\subsection{Water Tanks}

To make sure each "mesocosm" has enough space for plant growth and to stimulate soil horizons, each tank containing plants is at the height of $60 \mathrm{~cm}, 64$ mesocosm tanks are filled with $10 \mathrm{~cm}$ sand and topped with $25 \mathrm{~cm}$ of commercial topsoil, and the bottom area of each tank is $125 \mathrm{~cm}$ long $\times 75 \mathrm{~cm}$ wide. The total volume of each tank is 100 gallon.

\subsection{The Pipeline System}

The piping system of the automatic irrigation system starts from the huge tank (Figure 3), Brackish water is stored in the huge tank, and the piing system extends to assigned tanks. A water pump is installed at the outlet of huge tank, pumping out artificial seawater and distributing it to assigned water tank.

Fresh water comes out from the water pipe, with the push force of water pressure, fresh water can be to assigned tanks. The huge tank is equipped with a floating sensor, which can detect the salinity of the brine and regulate the amount of influent water, under the control of Arduino electronic platform.

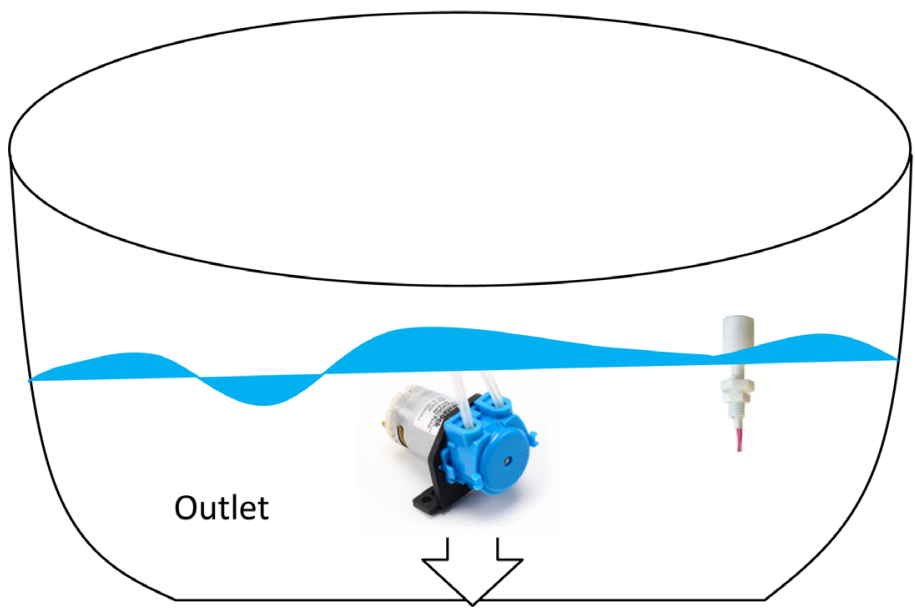

Water level

Figure 3. Detailed image of huge tank, indicating the location of peristaltic pump and floating sensor. 


\subsection{Electronic Component}

\subsubsection{Arduino 2560 Open-Source Electronic Platform}

Arduino 2560 open-source electronic platform is the controlling core of the entire irrigation system (Figure 4), it is connected with floating sensor, solenoid valves (Figure 5), peristaltic water pumps and a real-time clock, Arduino microcontroller has 54 digital input or output pins, they are responsible for controlling all the electronic components and solenoid valves of the entire irrigation system. The Arduino platform requires $12 \mathrm{v}$ input voltage, we have an external voltage regulator to stabilize the input voltage at $12 \mathrm{v}$. While the global system for mobile communication, real time clock, ultrasonic distance water level sensor require $5 \mathrm{v}$ input voltage, we use a relay to provide the electricity supply at $5 \mathrm{v}$.

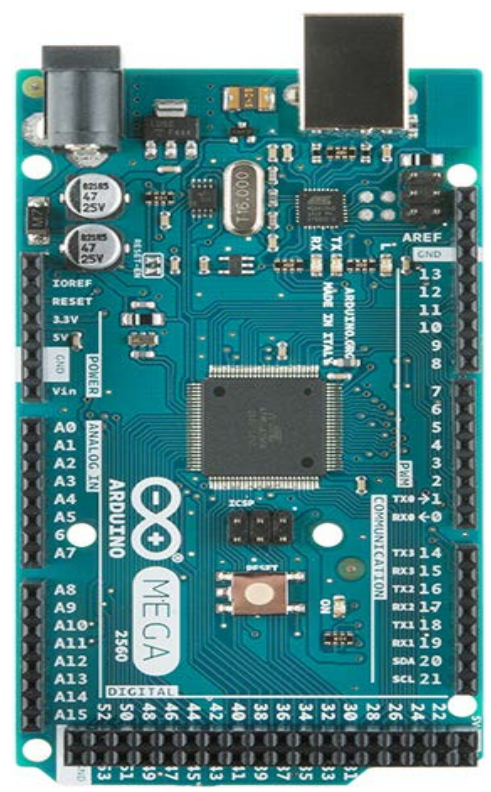

Figure 4. Arduino 2560 open-source electronic platform [11].

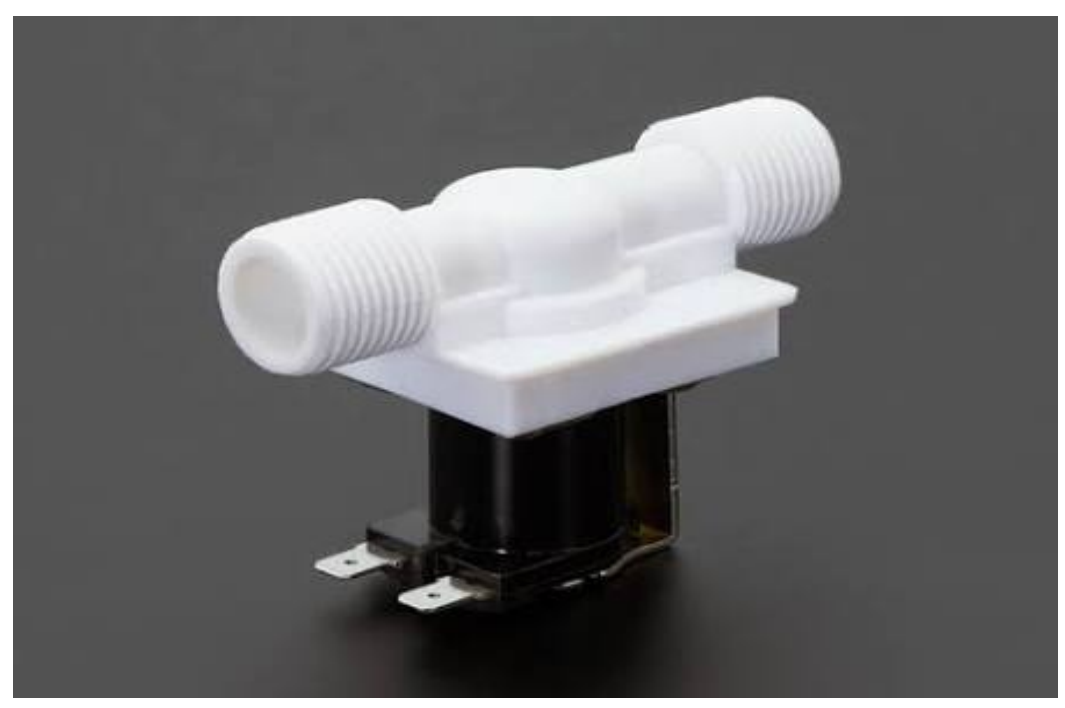

Figure 5. Detailed image of solenoid valve [12]. 


\subsubsection{The Global System for Mobile Communication}

The global system for mobile communication (GSM) is one of an expanded component of Arduino controller. GSM allows an Arduino board to send/receive short message service message and connect to the Internet, Radio modem and a subscriber identity module (SIM) card are used to exchange information using a radio modem and subscriber identity module (SIM) card to exchange information [13]. Considered unattended site regulation, GSM will send a daily remote status report to indicate whether the system is working properly.

\subsubsection{Real Time Clock}

The real time clock is connected to pins on the integrated circuit, it runs on an internal battery when there is a power outage to the irrigation system, the real time clock could still provide time and exchange information with Arduino micro-controller. It plays an important role in reading and regulating water level at specific time intervals. The time interval between a low tide and a high tide is $6 \mathrm{~h}$.

\subsubsection{Floating Sensor}

Our irrigation system uses floating sensors (Polypropylene LS-204) to measure water levels in each of the 64 tanks. Each of the floating sensors is installed inside a hollow PVC pipe in the tank (Figure 6). The bottom of PVC pipe reaches the bottom of tank, its top is higher than the upper edge of tank, Floating sensor measures water level and salinity based on height of float and the ratio of submerged length/entire float length. Each submerged depth corresponds to a specific salinity (Figure 7).

Above the huge tank, a switch is installed to add Homarsel salt, the raw material for artificial seawater preparation. If water level is lower than threshold, switch is on to add assigned amount of salts, until it reaches salinity at $0.1 \mathrm{ppt}$, switch turns to off.

The key to the work of floating sensor is to determine the threshold for opening/closing valves, we will discuss it in detain in the "Software Design" section.

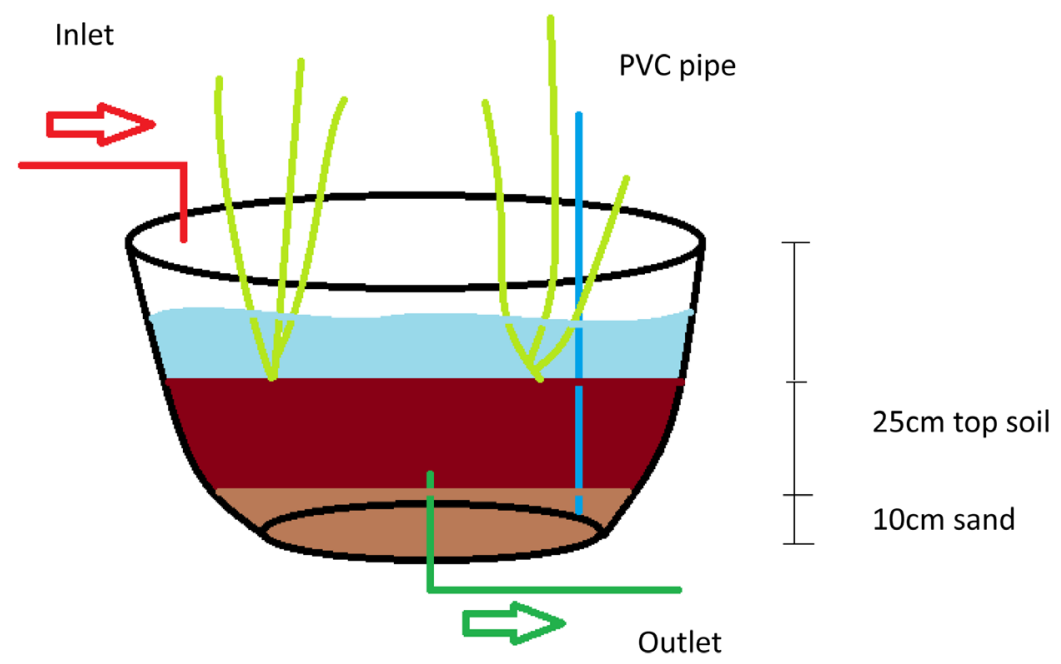

Figure 6. High tide image of water tank. Inside of the hollow PVC pipe, the floating sensor cannot be shown on the figure. 
When the irrigation system simulates a high tide, the sensor sends a message to the Arduino microcontroller, the solenoid valve (Figure 8) would open under the instruction of Arduino, determing input the $0.1 \mathrm{ppt}$ brackish water/0.05 ppt fresh water into assigned tanks through the pipe line system. When the irrigation system simulates a low tide, the sensor sends a message to the Arduino micro controller, the solenoid valve, next to outlet, would open to drain extra water out of tanks, until the soil surface is exposed in the air.

\subsubsection{Peristaltic Pump}

The peristaltic pump (Makeblock, DC 12.0) is installed in the huge tank, next to outlet, to pump accurate volume of brackish water into assigned tanks, and maintain the salinity stable at $0.1 \mathrm{ppt}$. The advantage of peristaltic pump is the two-direction distributing capacity, if extra water were pumped up forwards to tanks grown plants, it can start to turn in the opposite direction and suck water move backwards.

\subsection{Software Design}

The entire system is operated under the control of an open source Arduino integrated circuit. The software design is divided into four parts: 1) establish the code base, declare constants and variables; 2) Set the serial parameter, define

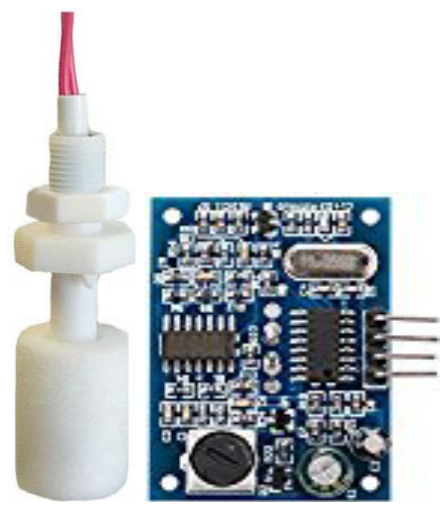

Figure 7. Detailed image of floating sensor. Each floating sensor is connected to specific pin on the Arduino [14].

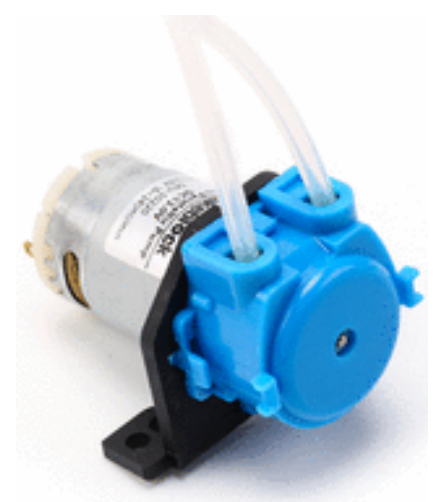

Figure 8. Peristaltic pump has no valve or sealing, silicone pipe can be replaced [15]. 
input/output, initialize the global mobile communication system; 3) Set the threshold, based on the reading of float sensor, Arduino decide whether the route should interrupt or continue; 4) Cycle route includes a series of programming commands to control water distribution.

\subsubsection{Part 1}

Import the library file, Arduino is connected to the floating sensor and exchange information, Arduino is also connected to real time clock and update data on the internet. All variables are declared and a Boolean variable is created to record whether all floating sensor are running properly. If not, alert message will be sent online. All floating sensors, solenoid valves, tanks holding water are numbered then assigned to the different pins on the integrated circuit. In addition, we define a series of constants, including the frequency of floating sensor reading, water level of thresholds to indicate the high tide/low tide, and distribute assigned volume of water to specified tank.

\subsubsection{Part 2}

First step is to define the baud rate of serial communication between the microcontroller and the floating sensor. Then start up the real time clock, synchronize the date and time with library file. The external voltage stabilizer (relay) ensures that the real time clock would not be reset when power is off. All peristaltic pumps and floating sensors are declared as inputs. The final step is to initialize the global mobile communication system and connect the SIM card to the network. At the end of the setup procedure, an SMS message would be sent indicating that the system has been reset.

\subsubsection{Part 3}

We define two interrupt route to read the volume of each water tank, and the data is collected by the floating sensor. Water distributed to different tanks requires a specific run route when connecting to a different serial port. In each route, the data is read from the appropriate port and a flag is triggered indicating that a string of data has been successfully received.

\subsubsection{Part 4}

This part of programming contains a replenishment of the huge water tank and the distributed routes of water to the 64 water tanks. The flow chart is shown in Figure 9. When the water distributing loop starts, the real time clock reports the current time and Arduino saves the data. The floating sensor reads water level every 5 minutes and 6 consecutive reads for 30 minutes.

Next, check the huge tank filled with artificial seawater. If the water level is below the assigned threshold, the pump will be on and push the water distributing to assigned tank, until the floating sensor in the tank sends message to indicate that the water level has reached the high tide/low tide threshold. Meanwhile, the floating sensor also measures the salinity of water inside. If salinity is not at the setting number, the switch above the huge water tank should be triggered and mix artificial sea water, until it reaches the salinity at $0.1 \mathrm{ppt}$. The pump 


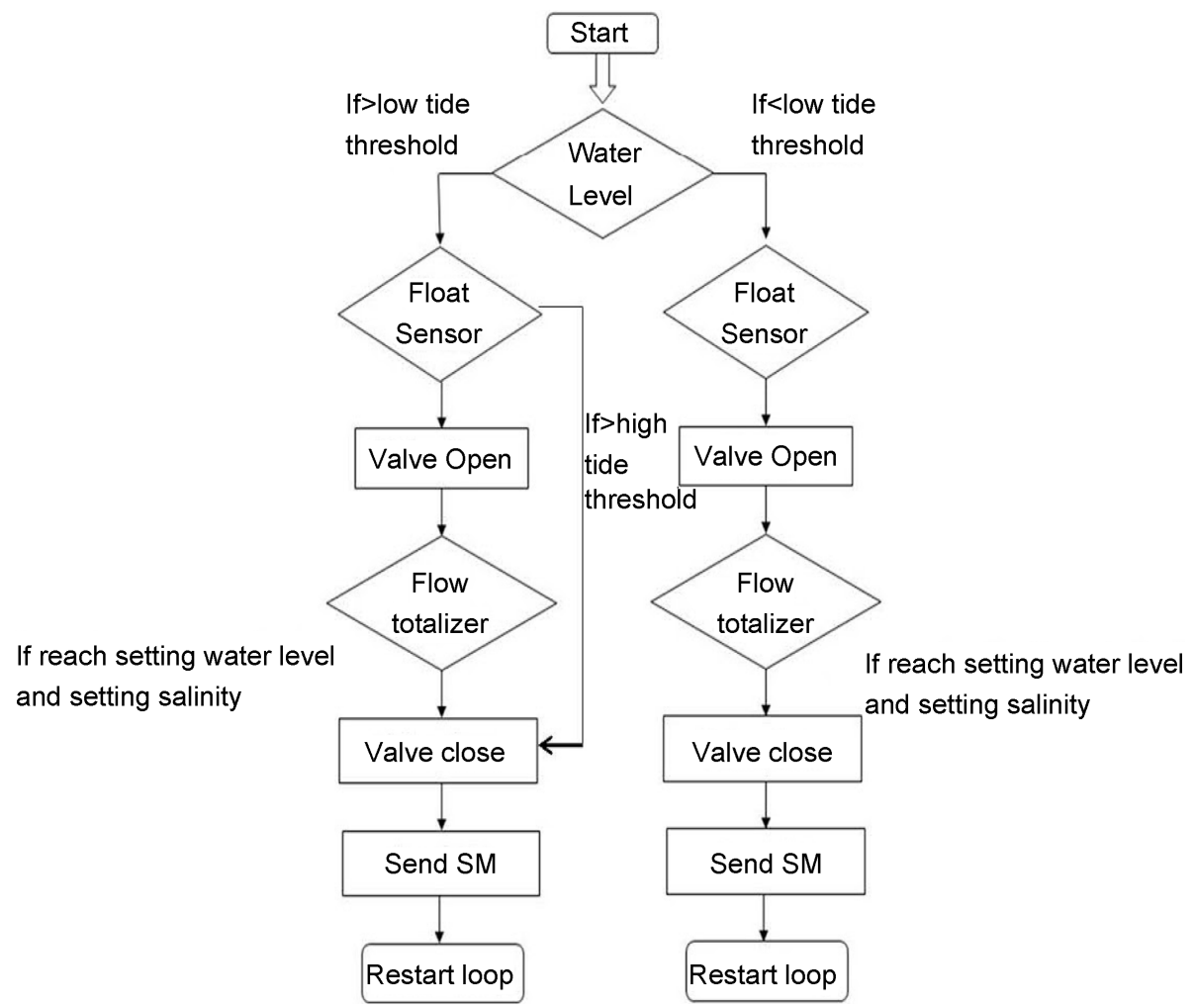

Figure 9. Main code indicates valve opens/closes based on the instruction of floating sensor, the connection is working by short message sent by GSM.

contained in the tank should keep working for 5 minutes to mix fresh water and brine.

If the real time clock indicates it is current in the high tide period, the irrigation system begins to allocate water to 64 water tanks. When the floating sensor detects that the water level reaches the set height, the solenoid valve would close. If the real time clock indicates it is current in the low tide period, the irrigation system starts to drain water out from 64 tanks. The valve on the bottom of water tank will open, extra water will discharge until the soil surface is exposed, then the valve closes. The discharged water can be recycled and used after filtration by the pipe system.

\section{System Failure and Alarm}

Multiple parts of the system are continuously monitored and checked whether they work smoothly. When the system error occurs, an SMS message would be sent to staff. The floating sensor in the large water tank needs to be checked, to ensure that there is enough salt water reserved and preventing the addition of excess salt water into water tanks. If the water level of the huge tank is lower than threshold of sea salts addition, an SMS message should be sent to warn the staff, sea salts should be supplemented.

In addition, water level in each tank should be detected constantly. If either holding water tank was not filled within the first 20 minutes, minutes the system will be shut down and send a "fault" SMS message, to notify the staff mainten- 
ance. The system will not continue running indefinitely.

\section{Hardware}

This section introduces the hardware components that make up this automatic irrigation system.

1) Water tank

The water tanks in this system are made of polyethylene materials, these black tanks are used as fresh water/brackish water storage. Each tank has a water outlet installed from the bottom of $10 \mathrm{~cm}$. As the water tank is filled water and stimulates high/low tides twice per day, water in each tank maintains for about 6 hours, which reduces the possibility of water chemistry alteration.

2) Water distribution

We use a PVC pipe (ABS Sch 40) with an outside diameter of 4 inch to connect the water tanks. The ABS pipe schedule 40 is more resistant to sun damage than normal PVC pipe, and can keep a constant drainage rate. Special multipurpose glue should be used to join pipe system.

3) Weather proofing

To reduce the risk of water damage to the Arduino microcontroller, solar panel controllers and battery, we installed a waterproof enclosure outside of them. The global system for mobile communication, real-time clock, and Arduino board are installed in a waterproof Box for a secondary case.

\section{Budget}

Table 1 provided a reasonable estimate of the cost for all work items, it listed electronic and hardware equipment and prices (June 2017) used in the automatic irrigation system. Similar items produced by other manufacturers could substitute for many of the individual items listed as follows.

Table 1. Cost estimation of the automatic irrigation system.

\begin{tabular}{|c|c|c|c|c|}
\hline Equipment & Brand & Quantity/length & Price $(\$)$ & Note \\
\hline $\begin{array}{c}\text { Arduino Mega } \\
2560 \text { R3 }\end{array}$ & $\begin{array}{l}\text { Arduino, } \\
\text { Ivera, Italy }\end{array}$ & 1 & 45.95 & \\
\hline $\begin{array}{l}\text { Arduino GSM } \\
\text { shield V2 }\end{array}$ & $\begin{array}{l}\text { Arduino, } \\
\text { Ivera, Italy }\end{array}$ & 1 & 69 & \\
\hline SIM card & Ctexcel & 1 & 9 monthly & $\begin{array}{l}\text { Subscriber identity module } \\
\text { for cellular service }\end{array}$ \\
\hline $\begin{array}{l}\text { Module precision } \\
\text { Real time clock }\end{array}$ & $\begin{array}{c}\text { Donop DS3231 } \\
\text { AT24C32 IIC }\end{array}$ & 1 & 4 & \\
\hline Floating sensor & Polypropylene LS-204 & 66 & 6.95 & \\
\hline $\begin{array}{l}\text { Peristaltic } \\
\text { pump }\end{array}$ & $\begin{array}{c}\text { Makeblock } \\
\text { DC } 12.0\end{array}$ & 1 & 35.99 & \\
\hline Water tank & & 64 & 30 & \\
\hline Huge water tank & & 1 & 68 & \\
\hline \multirow[t]{2}{*}{ PVC pipe } & ABS Sch 40 & 1818 & $1.13 / \mathrm{ft}$ & \\
\hline & & total & $4664.64 /$ month & \\
\hline
\end{tabular}




\section{Conclusion}

An in situ experiment is an effective method to study the impact of sea water intrusion on coastal marsh ecosystem, however, it requires a lot of physical labor and daily attendance, to some certain extent, reduces the efficiency of research. In order to simulate the sea water intrusion of coastal wetland under controlled conditions (soil, water chemistry, plant composition), we designed an automated irrigation system to explore the impact of half day tide on common wetland plants, and stimulate sea level rise patterns that are relevant to the Connecticut River. The system distributes artificial brackish water/fresh water to the designated tank and drains brackish water/fresh water out of tank every $6 \mathrm{~h}$. The system only requires monthly on-site inspections. Data can be sent online via the mini Arduino dashboard. In the future, potentially we will further explore the effects of seawater invasion on the growth of Carexstricta, Spartinapectinata, Typhalatifolia, Phragmitesaustralis, the effects of salinity gradients on wetland plant, soil microbial community alteration, ecosystem carbon cycle and nitrogen cycle and greenhouse gas emission rate.

\section{References}

[1] Environment Protection Agency. Coastal Wetlands. https://www.epa.gov/wetlands/coastal-wetlands

[2] Ferrarezi, R.S., Dove, S.K. and van Iersel, M.W. (2015) An Automated System For Monitoring Soil Moisture and Controlling Irrigation Using Low-Cost Open-Source Microcontrollers. Hort Technology, 25, 110-118.

[3] Miller, L.P. and Long, J.D. (2015) A tide Prediction and Tide Height Control System for laboratory Mesocosms. PeerJ, 3, e1442. https://doi.org/10.7717/peerj.1442

[4] Neubauer, S.C. (2013) Ecosystem Responses of a Tidal Freshwater Marsh Experiencing Saltwater Intrusion and Altered Hydrology. Estuaries and Coasts, 36, 491507. https://doi.org/10.1007/s12237-011-9455-X

[5] Kao-Kniffin, J., Freyre, D.S. and Balser, T.C. (2010) Methane Dynamics across Wetland Plant Species. Aquatic Botany, 93, 107-113. https://doi.org/10.1016/j.aquabot.2010.03.009

[6] Lawrence, B.A., Lishawa, S.C., Hurst, N., Castillo, B.T. and Tuchman, N.C. (2017) Wetland Invasion by Typha $\times$ glaucaincreases Soil Methane Emissions. Aquatic Botany, 137, 80-87. https://doi.org/10.1016/j.aquabot.2016.11.012

[7] Mozdzer, T.J. and Megonigal, J.P. (2013) Increased Methane Emissions by an Introduced Phragmitesaustralis Lineage under Global Change. Wetlands, 33, 609-615. https://doi.org/10.1007/s13157-013-0417-X

[8] Martin, R.M. and Moseman-Valtierra, S. (2015) Greenhouse Gas Fluxes Vary between Phragmitesaustralis and Native Vegetation Zones in Coastal Wetlands along a Salinity Gradient, Wetlands, 35, 1021-1031. https://doi.org/10.1007/s13157-015-0690-y

[9] Connecticut Weather and Live, Tides Charts and Graphs for Connecticut River. http://wtnh.com/weather/tides/

[10] Lee, D.Y., De Meo, O.A., Thomas, R.B., Tillett, A.L. and Neubauer, S.C. (2016) Design and Construction of an Automated Irrigation System for Simulating Saltwater Intrusion in a Tidal Freshwater Wetland. Wetlands, 36, 889-898. 
https://doi.org/10.1007/s13157-016-0801-4

[11] Arduino 2560 Open-Source Electronic Platform Home Page (2017).

https://www.sparkfun.com/products/11061

[12] Solenoid Valve Home Page (2017). https://www.adafruit.com/product/997?gclid=COv3t-qsqdMCFZKLswodBrsEbQ

[13] Parameswaran, G. and Sivaprasath, K. (2016) Arduino Based Smart Drip Irrigation System Using Internet of Things. International Journal of Engineering Science and Computing, 6, 449-456.

[14] Floating Sensor Home Page (2017). https://www.liquidlevel.com/product/polypropylene-single-level-float-switch-204/

[15] Peristaltic Pump Home Page (2017). http://www.studica.com/us/en/Makeblock/micro-peristaltic-pump-dc120v/50220.ht ml?ex ref=nextag feed\&amp;utm source=feed\&amp;utm medium=referral\&amp; utm campaign=nextag

Submit or recommend next manuscript to SCIRP and we will provide best service for you:

Accepting pre-submission inquiries through Email, Facebook, LinkedIn, Twitter, etc. A wide selection of journals (inclusive of 9 subjects, more than 200 journals)

Providing 24-hour high-quality service

User-friendly online submission system

Fair and swift peer-review system

Efficient typesetting and proofreading procedure

Display of the result of downloads and visits, as well as the number of cited articles Maximum dissemination of your research work

Submit your manuscript at: http://papersubmission.scirp.org/

Or contact eng@scirp.org 